\title{
Evaluation of a lysostaphin-fusion protein as a dry-cow therapy for Staphylococcus aureus mastitis in dairy cattle
}

\author{
K. J. Hoernig, ${ }^{*}$ D. M. Donovan,† P. Pithua, ${ }^{*}$ F. Williams III,† and J. R. Middleton*1 \\ *Department of Veterinary Medicine and Surgery, University of Missouri, Columbia 65211 \\ †USDA, Beltsville, MD 20705 \\ ¥Veterinary Medical Diagnostic Laboratory, University of Missouri, Columbia 65211
}

\begin{abstract}
This study evaluated the efficacy of a recombinant lysostaphin fused to a protein transduction domain (rLYS-PTD) as a dry-cow therapy for the treatment of experimentally induced chronic, subclinical Staphylococcus aureus mastitis. Twenty-two Holstein dairy cows were experimentally infected with Staph. aureus in a single pair of diagonal mammary quarters approximately $45 \mathrm{~d}$ before dry off. Staphylococcus aureusinfected mammary quarters of cows were randomly assigned to 1 of 2 treatment groups at dry off: (1) 279 $\mathrm{mg}$ of rLYS-PTD in $50 \mathrm{~mL}$ of vehicle $(\mathrm{n}=11$ cows; 22 quarters) or (2) $50 \mathrm{~mL}$ of vehicle solution $(\mathrm{n}=11$ cows; 22 quarters) by intramammary infusion. All cows were followed for $30 \mathrm{~d}$ postpartum to determine cure rates using bacteriologic culture, somatic cell counts, and clinical mastitis scores. No cures were recorded in either the treatment or control groups. Milk somatic cell count, bacterial colony counts, and mastitis scores did not significantly differ between treatment groups. In conclusion, rLYS-PTD was not an effective dry-cow therapeutic for chronic, subclinical Staph. aureus mastitis at the tested dose and formulation.
\end{abstract}

Key words: Staphylococcus aureus mastitis, lysostaphin, dry-cow therapy

\section{INTRODUCTION}

Staphylococcus aureus is a gram-positive, facultatively anaerobic, nonmotile, nonsporulating, catalasepositive, coagulase-positive, hemolytic coccus that is regarded as one of the most common contagious mastitis pathogens (Harmon, 1994). The major reservoir for infection is the cow's mammary gland (Davidson, 1961;

Received December 18, 2015.

Accepted February 14, 2016.

${ }^{1}$ Corresponding author: middletonjr@missouri.edu
Frost, 1975), and cow-to-cow transmission usually occurs during milking via the milking machine or other fomites that come in contact with the teat skin during milking (Saperstein et al., 1988; Fox et al., 1991). The introduction of the 5-point mastitis control program in the 1960s has led to a significant reduction in the prevalence of Staph. aureus IMI on many farms (Hillerton et al., 1995; Nagahata et al., 2007). However, Staph. aureus can still affect individual farms and, depending on chronicity and transmissibility within herd, it can be difficult to eradicate (Smith et al., 1998). Research in the last few decades has shown that Staph. aureus that cause IMI are not a homogeneous group, with some strains being host-adapted and highly contagious and others being sporadically isolated and tending not to be the predominant cause of IMI in a given herd (Middleton and Fox, 2002; Graber et al., 2009; van den Borne et al., 2010; Ote et al., 2011)

Treatment of Staph. aureus mastitis with either parenteral or intramammary antimicrobials during the lactating and nonlactating periods has been met with variable results. Cure rates ranging from 3 to $76 \%$ using conventional, lactating cow antimicrobial treatment strategies have been reported (Barkema et al., 2006). Cure rates following antimicrobial therapy are affected by increasing cow age, increasing SCC, increasing chronicity of infection, increasing bacterial counts, and increasing numbers of mammary quarters infected (Barkema et al., 2006). In their review, Barkema et al. (2006) concluded that "treatment of young animals with penicillin-sensitive Staph. aureus infections are often justified based on bacteriological cure and economic outcome, whereas treatment of older animals, chronic infections, or penicillin-resistant isolates should be discouraged." Furthermore, prolonged duration of therapy has been reported to improve cure rates (Barkema et al., 2006; Roy and Keefe, 2012).

The recombinant form of the antimicrobial bacteriocin lysostaphin has been studied as an alternative to conventional antimicrobials for the treatment of Staph. aureus IMI. Recombinant lysostaphin, a pep- 
tidoglycan hydrolase bacteriocin produced by Staphylococcus simulans, was first documented by Schindler and Schuhart (1964). Recombinant lysostaphin is a zinc-metalloenzyme that hydrolyzes the glycyl-glycine bonds of the pentaglycine cross-bridge of the Staph. aureus cell wall peptidogylcan (Wadstrom and Vesterberg, 1971; Recsei et al., 1987). Early studies used recombinant lysostaphin (rLYS) to treat Staph. aureus mastitis in rodent models and demonstrated mammary infection clearance rates greater than $87 \%$, suggesting staphylolytic activity in vivo without deleterious effects on the host (Sears et al., 1988; Bramley and Foster, 1990). Oldham and Daley (1991) studied the efficacy of rLYS in lactating dairy cows with experimentally induced Staph. aureus IMI (50-100 cfu of strain ATCC 29740). A single intramammary infusion of $100 \mathrm{mg}$ of rLYS in $60 \mathrm{~mL}$ of PBS cleared $95 \%$ of treated quarters for a minimum of 1 milking ( $12 \mathrm{~h}$ ). However, despite rLYS maintaining in vitro antimicrobial activity for 72 $\mathrm{h}$, most mammary quarter IMI relapsed within $72 \mathrm{~h}$ of treatment. When compared with conventional intramammary antibiotic therapies (penicillin G, cephapirin sodium in PBS, and cephapirin sodium in peanut oil), rLYS ( $20 \%$ cure) was superior to penicillin G ( $0 \%$ cure) and equivalent to cephapirin sodium in PBS (29\% cure; Oldham and Daley, 1991). Cephapirin sodium in peanut oil was most effective with a cure rate of $57 \%$. The poor cure rate of rLYS was hypothesized to be due to intracellular Staph. aureus not being killed by rLYS and thus contributing to the observed rapid relapse of infection.

Researchers at the USDA (Beltsville, MD) fused rLYS to the protein transduction domain (PTD) of human immunodeficiency virus trans-activator of transcription (HIV-TAT) using PCR cloning and expression in BL21 (DE3) Escherichia coli (Patent No. US8383102 B2; Donovan, 2013). This PTD has previously been shown to facilitate passage of molecules greater than 30,000 Da into mammalian cells (Fawell et al., 1994; Wadia et al., 2004). Preliminary work using the fusion product of rLYS to the PTD HIV-TAT (rLYS-PTD) showed that this method could successfully eliminate intracellular Staph. aureus from cultured bovine mammary epithelial cells (Mac-T cells) in both culture medium and sterile milk at $37^{\circ} \mathrm{C}$ (data not shown). However, further testing revealed a reduction in bioactivity. Whereas Oldham and Daley (1991) determined the MIC of rLYS to be $0.03 \mu \mathrm{g} / \mathrm{mL}$, the MIC of rLYS-PTD was found to be 10 $\mu \mathrm{g} / \mathrm{mL}$. The purpose of the current study was to test the efficacy of rLYS-PTD as a dry-cow therapy in dairy cattle with experimentally induced chronic, subclinical Staph. aureus IMI.

\section{MATERIALS AND METHODS}

\section{Study Design}

Twenty-two late-lactation Holstein-Friesian dairy cattle that were confirmed pregnant in late gestation were studied. Group size calculations were premised on $<1 \%$ cure rate in controls and a $40 \%$ [anticipated to double the cure rate of rLYS reported by Oldham and Daley (1991) because of ex vivo intracellular activity in cultured cells] cure rate in the rLYS-PTD-treated group with a power of 0.8 and $P<0.05$ using sample size for proportions (SigmaStat 12.0, San Rafael, CA), which yielded a sample size of 21 mammary quarters per group. The cows ranged from first through fifth parity and consisted of 4 primiparous and 18 multiparous cows with a median parity of 3 . All procedures were approved by the University of Missouri Animal Care and Use Committee. All animals were housed at the University of Missouri Foremost Dairy Research Center (Columbia, MO) in sand-bedded freestalls. During lactation, cows were milked twice daily at 0700 and 1900 h. Cows were fed a TMR balanced according to NRC (2001) requirements for stage of lactation or dry period. During the dry period, cows had access to pasture in addition to their dry-cow TMR.

Staphylococcus aureus IMI was experimentally induced in all studied cattle at approximately $105 \mathrm{~d}$ from expected calving date ( $\sim 5 \mathrm{~d}$ before dry-off). Before intramammary challenge with Staph. aureus, mammary quarter foremilk samples were collected from all 4 mammary quarters of each cow at $-3,-2$, and $-1 \mathrm{~d}$ relative to challenge dosing ( $\mathrm{d} 0$ ) for bacterial culture and milk SCC enumeration. All challenged mammary quarters were free of major mastitis pathogen IMI before challenge. Staphylococcus aureus IMI were established using a previously published protocol (Middleton et al., 2006). Briefly, 2 diagonal mammary quarters on each cow were infused via a sterile teat cannula with Staph. aureus strain ATCC 29740 (American Type Culture Collection, Manassas, VA) once daily after complete milk-out during the morning milking for 3 consecutive days. Each daily infusion dose was suspended in $10 \mathrm{~mL}$ of sterile PBS for administration. Diagonal patterns of either right front (RF) and left rear (LR) or left front ( $\mathbf{L F})$ and right rear (RR) were randomly and equally distributed between cows. Due to varying stages of gestation and to decrease variation in time from Staph. aureus intramammary challenge to dry-off, cows were infected with Staph. aureus in 2 phases.

In phase 1, 12 cows (24 mammary quarters) were challenged, and in phase 2, 10 cows (20 mammary 
quarters) were challenged. In phase 1 , the initial 3-d geometric mean dose ranged from 118 to $149 \mathrm{cfu} /$ quarter. Six mammary quarters on 4 cows were consistently culture negative for Staph. aureus after challenge and required repeated challenge doses to establish an IMI. The 6 uninfected mammary quarters were challenged again $5 \mathrm{~d}$ after the initial challenge dose with another 3 -d dosing regimen, having a 3-d geometric mean dose ranging from 501 to $567 \mathrm{cfu} /$ quarter. After this second 3 -dose regimen, 1 of the 6 mammary quarters became consistently culture positive for Staph. aureus. Three of the remaining 5 uninfected mammary quarters on 3 cows were challenged again 5 to $6 \mathrm{~d}$ after the second challenge regimen with a 3 -d geometric mean dose of Staph. aureus ranging from 2,247 to 2,801 cfu/quarter, and all 3 quarters became infected. The remaining 2 quarters on 2 cows received a single follow-up challenge dose of 1,995 or 11,720 cfu/quarter at 4 or $6 \mathrm{~d}$ after the second $3-\mathrm{d}$ challenge dose regimen, respectively. The dose of 11,720 cfu occurred due to a 10-fold dilution error. Both of these quarters became infected after these final doses. Due to the need for repeated dosing of some mammary quarters in phase 1 , the challenge dose was increased in phase 2 . In phase 2 , the initial 3 -d geometric mean dose ranged from 459 to $522 \mathrm{cfu}$, and all mammary quarters became infected after the initial 3-d dosing regimen. Mammary quarter foremilk samples were aseptically collected daily for $7 \mathrm{~d}$ following the last intramammary challenge dose, and then twice weekly (Monday and Thursday) until dry off, and immediately before dry off for bacterial culture and SCC enumeration to confirm IMI status.

At dry off, cows were randomly assigned using a random number generator to 1 of 2 groups: (1) rLYSPTD ( $\mathrm{n}=11$ cows; 22 quarters) or $(2)$ control $(\mathrm{n}=11$ cows; 22 mammary quarters), such that equal numbers of phase 1 and 2 challenge dose cows and mammary quarters were distributed between groups. Following complete milk-out on the day of dry off, treatments were aseptically administered via sterile teat cannulas into the 2 Staph. aureus-infected quarters of each cow. The rLYS-PTD group received $279 \mathrm{mg}$ of rLYS-PTD in $50 \mathrm{~mL}(5.58 \mathrm{mg} / \mathrm{mL})$ of vehicle solution $(50 \mathrm{mM}$ $\mathrm{NaH}_{2} \mathrm{PO}_{4}, 300 \mathrm{~m} M \mathrm{NaCl}, 30 \%$ glycerol, $\mathrm{pH} 8.0$ ), and the control group received $50 \mathrm{~mL}$ of the vehicle solution. All teats of all cows were sealed with a commercial internal teat sealant (Orbeseal, Zoetis, Florham Park, NJ). Cows were not treated with any other parenteral or intramammary antimicrobials during the study.

The in vitro MIC for rLYS-PTD was previously determined to be $10 \mu \mathrm{g} / \mathrm{mL}$ (Patent No. US8383102 B2; Donovan, 2013). The treatment dose of $279 \mathrm{mg}$ of rLYS-PTD was based on achieving a predicted intramammary concentration greater than the MIC and the limitation of the highest concentration of endotoxin-free protein that could be purified at a large scale. In addition, the maximum amount of protein (in milligrams) that would stay in solution was predicted to be $5.58 \mathrm{mg} / \mathrm{mL}$, and $50 \mathrm{~mL}$ was found to be the maximum amount that could be easily infused, giving a total dose of $279 \mathrm{mg}$. At this dose, it was predicted that the concentration of rLYS-PTD would be above the predicted MIC in the milk compartment even if the cow continued to secrete up to $27.2 \mathrm{~kg}$ (60 lbs) of milk into a single mammary quarter after dry-off [60 lbs of milk $=6.82$ gallons $=25.8 \mathrm{~L} ; 279 \mathrm{mg} /(25,800 \mathrm{~mL}$ $+50 \mathrm{~mL}$ of vehicle solution) $=10.7 \mu \mathrm{g} / \mathrm{mL}$. Finally, a glycerol-based vehicle solution was selected over the PBS carrier described by Oldham and Daley (1991) because it was reported elsewhere that glycerol might increase distribution within the gland (Jakubczak et al., 2010). Investigators administering treatments and collecting follow-up data were blinded to treatments throughout the study.

All animals were monitored for general health over the dry period, and followed for the first 30 DIM to evaluate IMI status. To determine IMI status after calving, mammary quarter foremilk samples were aseptically collected for bacterial culture and SCC enumeration during the morning milking within $24 \mathrm{~h}$ of calving (sample period 1) and then twice weekly (Monday and Thursday) until the end of study at 30 DIM (sample periods 2-10). Additionally, cows were evaluated at each sampling for clinical mastitis using a previously published mastitis scoring system (Middleton et al. 2006), where MS0 = normal milk and udder; MS1 = abnormal milk, but palpably normal udder; MS2 = abnormal milk and inflamed udder; and MS3 = abnormal milk, inflamed udder, and systemically ill cow.

After the 30-d follow-up period, 14 of the 22 cattle were euthanized by captive-bolt stunning followed by intravenous injection of a concentrated potassium chloride solution until the heart stopped. Immediately following euthanasia, the mammary glands were removed from the 14 cows $(n=7$ rLYS-PTD cows and $n$ $=7$ control cows) and submitted to the University of Missouri Veterinary Medical Diagnostic Laboratory for gross and histologic examination. The 8 remaining cows were used for follow-up studies and then euthanized in the same manner later. Postmortem examinations of the udders on the latter 8 cows were not performed because the follow-up studies would have confounded the results.

\section{Laboratory Methods}

Milk samples for bacterial culture were stored at $-20^{\circ} \mathrm{C}$ after collection until processed (storage time: 24 
$\mathrm{h}$ to $7 \mathrm{~d}$ ). On the day of bacterial culture, milk samples were thawed at room temperature $\left(25^{\circ} \mathrm{C}\right)$ and cultured by streaking $10 \mu \mathrm{L}$ of milk using a calibrated disposable loop onto Columbia agar containing $5 \%$ sheep blood (Thermo Scientific, Lenexa, KS). Samples were incubated for 18 to $24 \mathrm{~h}$ at $37^{\circ} \mathrm{C}$ followed by an additional $24 \mathrm{~h}$ at room temperature. Bacterial growth was evaluated according to National Mastitis Council guidelines (Hogan et al., 1999). Staphylococcus aureus growth was determined by the presence of catalase-positive, coagulase-positive, moist, pigmented colonies surrounded by zone(s) of complete or incomplete hemolysis at 24 and $48 \mathrm{~h}$. Staphylococcus aureus bacterial counts were enumerated and recorded as colony-forming units per milliliter. Staphylococcus aureus isolates were subcultured on Columbia agar with 5\% sheep blood and isolates were stored in phosphate-buffered glycerol at $-80^{\circ} \mathrm{C}$ for future characterization.

Milk samples for SCC were placed in vials containing a 2-bromo-2-nitropropane-1,3-diol preservative tablet (Broad Spectrum Microtabs II, D\&F Control Systems Inc., Dublin, CA), stored at $4^{\circ} \mathrm{C}$, and shipped at least once weekly to a commercial laboratory for enumeration (Mid-South Dairy Records, Springfield, MO) using an automated counter (Somacount 300, Bentley Instruments, Chaska, MN).

Postmortem, mammary glands from the first 14 cows to complete the study (30 DIM) were examined grossly for the presence of abscesses. Representative sections of each mammary quarter parenchyma were fixed in $10 \%$ buffered formalin and paraffin-embedded for staining. Sections of tissue were stained with hematoxylin and eosin and microscopically examined for leukocyte infiltration and the presence of staphylococcal microabscesses. The degree of inflammatory change was recorded on a scale of 1 to 3 , where $1=$ no-to-few leukocytes present, $2=$ moderate leukocyte infiltration, or 3 = marked leukocyte infiltration (Trinidad et al., 1990).

To confirm that the Staph. aureus isolated from mammary quarters during the first 30 DIM was the infused ATCC 29740 strain and not a new IMI with a different strain of Staph. aureus, isolates from dry off, parturition, and 30 DIM were evaluated for relatedness to each other and the reference ATCC 29740 Staph. aureus strain by pulsed-field gel electrophoresis (PFGE) according to the method described by Middleton et al. (2002). When isolates were not available for these sample periods, comparisons were made using Staph. aureus isolates from the next closest sampling period within either the pre-dry or postpartum period. Briefly, SmaI (Invitrogen, Carlsbad, CA) digests of staphylococcal DNA were separated by PFGE in a $1 \%$ agarose gel (Pulsed Field Certified Agarose, Bio-Rad, Hercules, $\mathrm{CA}$ ) immersed in $0.5 \%$ Tris-borate-EDTA (TBE) buffer at $14^{\circ} \mathrm{C}$ for $20 \mathrm{~h}$ at $6 \mathrm{~V} / \mathrm{cm}$ with a 5 - to 50 -s pulse time on a PFGE machine (CHEF DRIII, Bio-Rad). Isolates were compared visually with the reference ATCC 29740 strain and each other. Isolates with identical PFGE banding patterns (i.e., same numbers of bands of alike molecular weights were regarded as the same strain; Tenover et al., 1995).

\section{Data Analysis}

Days infected before dry off, days dry, and challenge doses were compared between treatment and control groups using a Mann-Whitney rank sum test. The geometric mean of each mammary quarter's 3-dose challenge regimen was calculated, and median of these geometric means was compared between groups using the Mann-Whitney rank sum test.

For the purpose of data analysis, a cure was defined when a mammary quarter was culture negative for Staph. aureus ATCC 29740 at all of the 10 postpartum sampling periods (30 DIM). A persistent IMI was defined as the detection of Staph. aureus ATCC 29740 from at least 1 postpartum foremilk sample collected during the 10 postpartum samplings. Cure rates and histopathology results were compared using chi-square analysis. Time to detection of Staph. aureus IMI by milk culture during the first 30 DIM was compared between treatment and control groups using a survival analysis plot and compared between groups using the log rank test.

Data collected at dry off (immediately pretreatment; sample period 0) and the 10 postpartum sample periods were compiled in a spreadsheet (Excel, Microsoft, Redmond, WA). The SCC and bacterial counts $(\mathrm{cfu} / \mathrm{mL})$ were log-transformed and compared between groups using a linear mixed model with treatment and sample period as fixed effects and cow and mammary quarter as random effects. Mastitis scores were transformed into binomial data representing either subclinical (MS $=0$ ) or clinical ( $\mathrm{MS}=1-3)$ mastitis and were compared between groups using the chi-square test. Significance for all statistical tests was $P<0.05$. Mastitis scores for $24 \mathrm{~h}$ postpartum (sample period 1) were not included in the data analysis due to scoring being confounded by colostrum and colostrum not being representative of normal milk.

\section{RESULTS}

Of the 44 mammary quarters receiving the initial 3-d challenge dose regimen, infection was successfully estab- 
lished in $86.4 \%(\mathrm{n}=38)$ of quarters. In the remaining quarters, infections were successfully established after receiving additional challenge doses (described above). Median (range) parity was $3(1-5)$ for the rLYS-PTD group and $3(1-4)$ for the control group $(P=0.331)$.
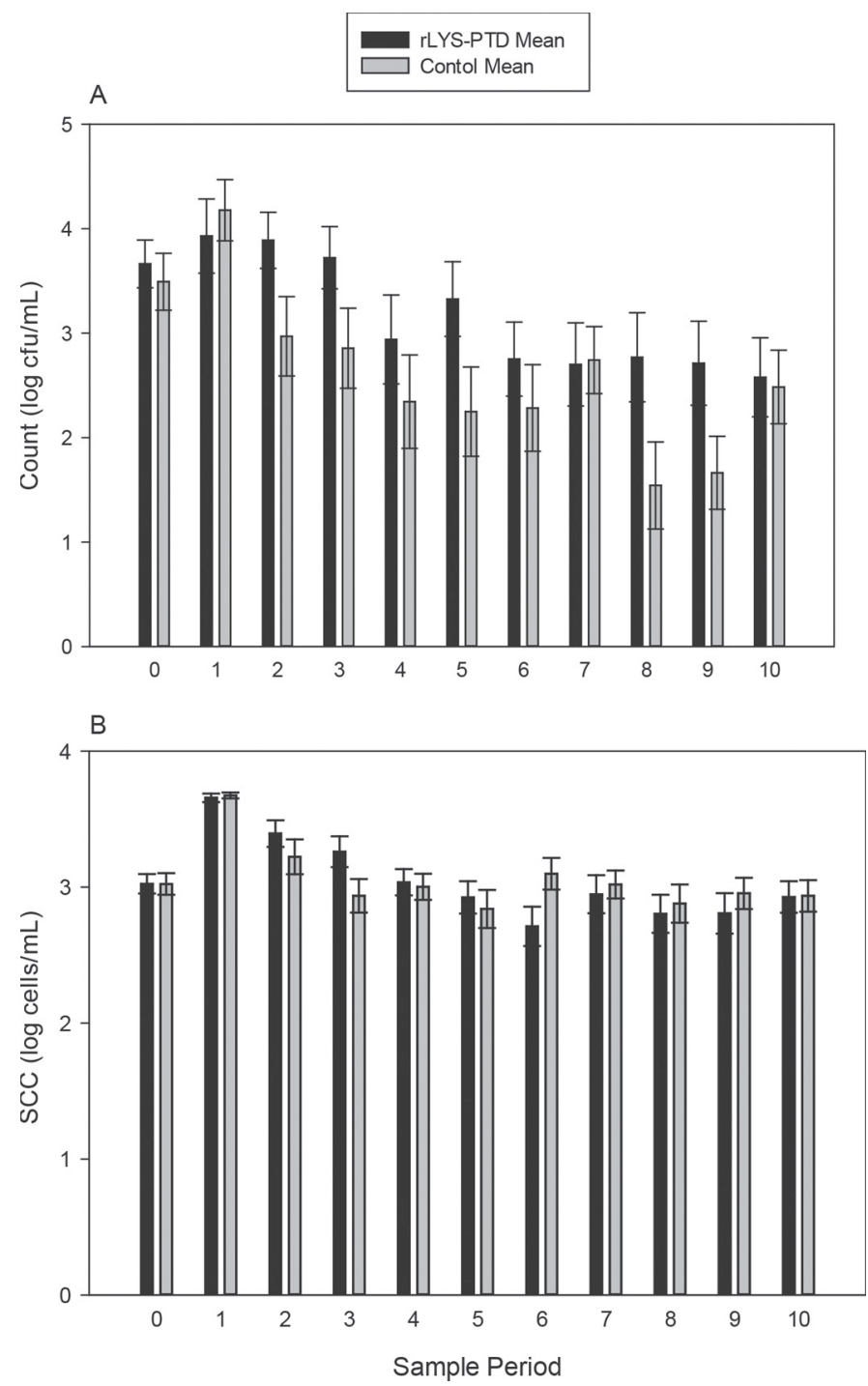

Figure 1. (A) Mean $( \pm \mathrm{SE})$ for bacterial count $(\log \mathrm{cfu} / \mathrm{mL})$ versus sample period by group. No differences were detected in counts between groups $(P=0.117)$ or sample periods $(P=0.104)$, and no significant interaction was noted between group and sample period postpartum $(P=0.409)$. Sample periods represent dry-off $(0)$, calving (1) and subsequent Monday/Thursday samplings postpartum (2-10). (B) Mean $( \pm \mathrm{SE})$ for SCC $(\log \mathrm{SCC} / \mathrm{mL})$ versus sample period by group. No differences in SCC were detected between groups $(P=0.832)$, and no group by sample period interaction $(P=0.193)$ was noted Mean SCC did differ between sample periods regardless of group $(P$ $=0.000)$. Sample periods represent dry-off $(0)$, calving (1), and subsequent Monday/Thursday samplings postpartum (2-10). rLYS-PTD = lysostaphin fused to a protein transduction domain.
The overall median (range) geometric mean challenge dose in rLYS-PTD-treated mammary quarters was 487 (118-11,720) and 336 (149-567) in control mammary quarters $(P=0.830)$. Median (range) number of milk cultures per mammary quarter performed between the final intramammary challenge dose and dry off was 21 (18-33), with the median (range) number of Staph. aureus culture-positive samples per mammary quarter being 19 (10-32) samples; this indicated that all mammary quarters used in the trial were chronically infected with Staph. aureus. Only 2 mammary quarters on 2 cows ( 1 rLYS-PTD and 1 control quarter) were Staph. aureus-positive on less than $74 \%$ of samples collected before dry-off (43 and 48\%, respectively), and both of these quarters were positive for Staph. aureus ATCC 29740 within $48 \mathrm{~h}$ of calving. Median (range) 24-h milk production immediately before dry off was $12.3(0.9-24.7) \mathrm{kg} /$ cow. Median (range) duration of infection at the time of dry off was $44(41-55) \mathrm{d}$ in the rLYS-PTD group and $48(42-55) \mathrm{d}$ in the control group $(P=0.72)$. The median (range) dry period length was $45(41-81) \mathrm{d}$ in the rLYS-PTD group and $49(37-68) \mathrm{d}$ in the control group $(P=0.45)$.

Within $24 \mathrm{~h}$ of calving, Staph. aureus was isolated from 39 of 44 mammary quarters $(\mathrm{n}=19$ rLYS-PTD; $\mathrm{n}=20$ control mammary quarters). Staphylococcus aureus was isolated from the 5 remaining mammary quarters at the second $(\mathrm{n}=3 ; 1-3$ DIM $)$, third $(\mathrm{n}=$ $1 ; 5$ DIM), and seventh ( $\mathrm{n}=1 ; 20$ DIM) sampling period. The median (range) time to detection of IMI in the rLYS-PTD and control groups were 1 (1-3) and 1 $(1-7)$ sample periods, respectively $(P=0.95)$. Overall, Staph. aureus was isolated from at least one mammary quarter foremilk sample of all Staph. aureus-challenged mammary quarters enrolled in the trial during the first 30 DIM.

Mean mammary quarter Staph. aureus culture yields $(\mathrm{cfu} / \mathrm{mL})$ did not differ between rLYS-PTD and control mammary quarters at any of the studied time points $(P=0.41 ;$ Figure $1 \mathrm{~A})$. Similarly, mean milk SCC did not differ between rLYS-PTD and control mammary quarters at any of the studied time points $(P=0.193$; Figure 1B). However, a significant decrease in SCC over the course of the postpartum period was observed $(P<$ 0.01), regardless of group.

At dry off, 2 challenged mammary quarters on a single rLYS-PTD cow (\#2295 RF and LR) and 2 challenged mammary quarters on a single control cow (\#2315 RF and LR) were scored as MS2. Cow \#2295 also scored MS1 in both unchallenged mammary quarters (RR and LF) at dry-off, one of which was bacterial culture negative (RR) and the other (LF) yielded 100 $\mathrm{cfu} / \mathrm{mL}$ of Staph. aureus, suggesting possible cross-con- 
tamination from the challenged mammary quarter(s). At the first sampling period postpartum when mastitis scores were evaluated (sample period 2), single challenged mammary quarters on 4 cows, 2 in rLYS-PTD (\#2150 RF and $2321 \mathrm{LF}$ ) and 2 in the control group (\#386 RR and $2295 \mathrm{LR}$ ), were scored MS1. Additionally, a single unchallenged mammary quarter on 3 of these cows (\#386 LR, $2150 \mathrm{LF}, 2295 \mathrm{RR}$ ) and 2 other cows (\#2302 LF and $2383 \mathrm{RR}$ ) were scored MS1 at the same sampling. Two of these quarters (\#2150 LF and 2295 RR) yielded growth of Staph. aureus, whereas the remaining quarters were culture negative. Note that the Staph. aureus IMI in the unchallenged RR quarter of cow \#2295 was present at dry-off. Cow \#2321 continued to score MS1 in the challenged LF quarter at all postpartum samplings (sample periods 2-10); this quarter ceased normal milk production but continued to secrete a serous fluid that was sampled for bacterial culture and consistently yielded Staph. aureus. Clinical mastitis scores (MS1) were additionally recorded in 1 unchallenged mammary quarter of a rLYS-PTD cow (\#2150 LF) during sample period 3, 1 challenged quarter of a rLYS-PTD cow (\#2204 LF) during sample period 4, and 1 unchallenged quarter of a control cow (\#2058 LR) during sample period 7, 2 of which were bacterial culture negative and 1 yielded a contaminated result. Notably, none of the mammary quarters exhibiting clinical signs at dry off or after calving were among the 6 mammary quarters that had to be rechallenged with higher doses of Staph. aureus in phase 1. All other mammary quarters scored MS0 throughout the period of study. Overall, the occurrence of clinical mastitis $(\mathrm{MS}>0)$ did not differ between rLYS-PTD treated and control mammary quarters $(P=0.11)$.

Mammary glands from 14 cows $(\mathrm{n}=7$ rLYS-PTD cows and $n=7$ control cows) were dissected and tissue sections submitted for histopathology. No micro-abscesses were recorded in any of the analyzed tissue sections. The median (range) inflammatory lesion scores in rLYS-PTD treated $(\mathrm{n}=14)$ and control treated (n $=14$ ) mammary quarters were $1(1-3)$ and $1.5(1-3)$, respectively $(P=0.71)$. Additionally, unchallenged, untreated mammary quarters $(\mathrm{n}=28)$ all had inflammatory lesion scores of 1 , which was significantly lower than the Staph. aureus-infected mammary quarters treated with rLYS-PTD or vehicle solution $(P<0.01)$.

Pulsed-field gel electrophoresis of the Staph. aureus isolates from the milk of mammary quarters collected during the first 30 DIM and the Staph. aureus isolated from milk of the same mammary quarters before treatment at dry off confirmed that all mammary quarters in both groups were infected with the ATCC 29740 challenge strain during the first 30 DIM.

\section{DISCUSSION}

Staphylococcus aureus is the most prevalent contagious mastitis pathogen on US dairy farms (USDA, 2008). After evading the host immune defenses, Staph. aureus can remain undetected and develop into a chronic IMI. A Staph. aureus IMI can become highly refractory to antibiotic therapy by the development of antibiotic resistance, generation of micro-abscesses, or staphylococcal invasion of phagocytes and mammary epithelial cells (Barkema et al., 2006). Hence, the need remains for a targeted and effective antimicrobial treatment for Staph. aureus mastitis.

Recombinant lysostaphin, a peptidoglycan hydrolase, has previously been studied as a potential treatment for Staph. aureus IMI. Oldham and Daley (1991) used rLYS as an intramammary treatment for experimentally induced Staph. aureus IMI in lactating cows and demonstrated it to be effective in temporarily $(24 \mathrm{~h})$ clearing extracellular staphylococci from milk. However, a poor overall cure rate of $20 \%$ was reported, and it was hypothesized that the poor cure rate was due to the inability of rLYS to kill Staph. aureus sequestered within the intracellular compartment. Additional work using 3 transgenic Jersey heifers that secreted 0.9 to $14 \mu \mathrm{g} /$ $\mathrm{mL}$ of rLYS (nonglycosylated variant) in their milk and were challenged with 3 different strains of Staph. aureus (1 strain in each of 3 mammary quarters) on either 2 ( $\mathrm{n}=2$ heifers) or 3 occasions ( $\mathrm{n}=1$ heifer) during the same lactation showed that Staph. aureus IMI could only be detected in milk after 3 of 21 intramammary challenges compared with IMI being detected after 34 of 48 intramammary challenges in 10 nontransgenic control cattle $(P=0.001$; Wall et al., 2005). Though encouraging, the latter report evaluated the ability of secreted rLYS to prevent Staph. aureus IMI rather than treat an existing IMI. Despite its novelty, the feasibility of rLYS-secreting cows on commercial dairies is currently of limited scope. Hence, the aim of the present study was to evaluate an rLYS fusion protein, shown in preliminary in vitro studies to kill intracellular Staph. aureus (Patent No. US8383102 B2; Donovan, 2013), to cure experimentally induced Staph. aureus mastitis in Holstein dairy cattle.

In contrast to Oldham and Daley (1991), who used a lactating cow therapy model, we chose a dry-cow therapy model for the present study to maximize enzyme concentrations and exposure time of Staph. aureus to rLYS-PTD in the mammary gland instead of potentially decreasing enzyme concentrations with successive twice-daily milking in a lactating model. Additionally, the use of commercially available antimicrobials as within-cow positive controls was not studied due 
to the relatively unknown pharmacokinetics of rLYSPTD and the potential for rLYS-PTD or a commercial antimicrobial to translocate into an adjacent treated mammary quarter, thereby confounding the results. Although more cows could have been enrolled to include a positive (commercial intramammary antimicrobial) control group, this was not feasible within the budgetary constraints of the study.

As in Oldham and Daley (1991), the present study used cows with experimentally induced Staph. aureus IMI (ATCC 29740). An experimental challenge model was chosen to minimize the variation caused by differences in duration of IMI and strain type that could have occurred with a natural infection model. In phase 1 , the target dose of $250 \mathrm{cfu} / \mathrm{d}$ for $3 \mathrm{~d}$ (Middleton et al., 2006) was not achieved in our initial infusion regimen. The final geometric mean daily dose ranged from 118 to 149 $\mathrm{cfu}$ /quarter, which was lower than the final daily dose of $180 \mathrm{cfu} /$ quarter reported previously (Middleton et al., 2006). Unlike the previous report (Middleton et al., 2006), 6 mammary quarters on 4 cows failed to develop a Staph. aureus IMI and were rechallenged one or more times, as detailed above. The failure of these 6 quarters to initially become infected may have been related to dose, mammary quarter effects, or cow effects. Notably, 2 of the 6 cows had 1 quarter each that developed a Staph. aureus IMI after the initial dosing regimen and only 1 quarter on each of these cows had to be rechallenged. In contrast, the 4 remaining quarters were on 2 cows, meaning that those cows did not become infected at all following initial dosing, suggesting possible resistance of those cows to the lower dose. Final establishment of IMI in these 6 quarters was not correlated with the development of clinical mastitis. Two of the 6 quarters were consistently MS0, 3 of the 6 quarters only exhibited an MS1 the day after the initial 3-d dosing, and the remaining quarter was clinical for $3 \mathrm{~d}$ (MS1, MS2, and MS2, respectively) after the initial 3-d dosing and only clinical (MS2) the day after the second dosing regimen. Also, none of these mammary quarters were among those that exhibited clinical mastitis scores at dry off or after calving. The dosing regimen in phase 2 may have been higher than needed but was chosen in an attempt to optimize initial infection rates based on the outcome of phase 1 .

For the present study, rLYS-PTD production methods were optimized to achieve a final concentration of $5.58 \mathrm{mg} / \mathrm{mL}$. The resulting dose per cow (279 $\mathrm{mg}$ in 50 $\mathrm{mL}$ ) was projected to exceed MIC in the gland at dry off and was able to be delivered in a single infusion, thus preventing repeated trauma to the teat canal from multiple infusions and predisposing the gland to environmental contamination (Middleton and Luby, 2008).
At the formulation and concentration used in the current study, rLYS-PTD proved ineffective in the treatment of a chronic Staph. aureus IMI, with an overall cure rate of $0 \%$. Additionally, rLYS-PTD treatment had no effect on milk SCC, Staph. aureus counts, or occurrence of clinical mastitis in the subsequent lactation. The progressive, postpartum decrease in SCC from calving to 30 DIM was not unexpected and has been previously documented as a normal occurrence at the onset of lactation (Sargeant et al., 2001).

The use of a dry-cow model presented several limitations in the evaluation of rLYS-PTD. One such limitation was the inability to administer repeated doses as reported by Oldham and Daley (1991). An additional limitation to the dry-cow model was the inability to collect repeated milk samples following treatment to determine immediate effects of rLYS-PTD on Staph. aureus bacterial counts as well as rLYS-PTD concentrations in milk over time. When cows are treated with conventional antimicrobial drugs during lactation, repeated dosing has been reported to increase cure rates (Barkema et al., 2006). However, in the dry cow, milk is not being removed 2 to 3 times daily, which means removal of residual drug does not occur as it would during lactation; thus, it might be predicted that drug concentrations are maintained due to the drug not being removed. This assumes that most of the drug stays in the milk compartment or mammary tissue. Based on maximum cow-level milk production measured at dry off $(24.7 \mathrm{~kg} /$ cow $=\sim 23.4$ $\mathrm{L}$ or $\sim 6 \mathrm{~L}$ per mammary quarter), the predicted approximate minimum (as some cows produced much less milk) concentration of rLYS-PTD in the milk compartment $24 \mathrm{~h}$ after infusion at dry off, assuming continued milk secretion into the gland, when 279 $\mathrm{mg}$ of rLYS-PTD was infused would be around 46.5 $\mu \mathrm{g} / \mathrm{mL}$, just over 3 times the concentration of rLYS secreted in the milk of transgenic heifers and 4 times the predicted MIC for rLYS-PTD based on in vitro studies by one of the authors (Patent No. US8383102 B2; Donovan, 2013).

A further complication to determining the appropriate dose of rLYS-PTD for treating an IMI is the fact that the cell specificity of the attached PTD is unknown. If the rLYS-PTD construct is carrying rLYS into all cells in the mammary gland, not just those infected with Staph. aureus, then it is assumed the required rLYS-PTD dose would become exponentially greater, hence providing another potential explanation for the lack of treatment efficacy compared with rLYS. Despite preliminary work confirming in vitro efficacy against extra- and intracellular Staph. aureus, it is difficult to know how the rLYS-PTD construct functions 
in vivo in the presence of milk components, immune cells, and mammary epithelium.

\section{CONCLUSIONS}

As a dry-cow therapy, at the dose and formulation tested, rLYS-PTD proved ineffective at clearing Staph. aureus IMI as measured in the subsequent lactation. Whereas the intramammary administration of exogenous lysostaphin compounds (i.e., rLYS) or rLYSPTD, have proven largely ineffective in the treatment of Staph. aureus IMI, the need remains for targeted therapeutic antimicrobials with the ability to kill both extra- and intracellular bacteria, such as Staph. aureus, that cause bovine mastitis.

\section{ACKNOWLEDGMENTS}

This work was supported by a grant from the USDA National Institute of Food and Agriculture (Washington, DC; Award No. 2010-65119-20576). The authors thank USDA Agricultural Research Service (Beltsville, MD) staff member Juli Foster-Frey, and University of Missouri staff Marion Butcher (College of Veterinary Medicine), John Denbigh and Eric Adkins (Foremost Dairy Farm), Julie Holle and Pamela Adkins (Department of Veterinary Medicine and Surgery), Kathryn Notch and Anna Delabar (students) for technical assistance.

\section{REFERENCES}

Barkema, H. W., Y. H. Schukken, and R. N. Zadoks. 2006. Invited review: The role of cow, pathogen, and treatment regimen in the therapeutic success of bovine Staphylococcus aureus mastitis. J. Dairy Sci. 89:1877-1895.

Bramley, A. J., and R. Foster. 1990. Effects of lysostaphin on Staphylococcus aureus infections of the mouse mammary gland. Res. Vet. Sci. 49:120-121.

Donovan, D. 2013. Fusion of peptidoglycan hydrolase enzymes to a protein transduction domain allows eradication of both extracellular and intracellular gram positive pathogens. United States Patent US8383102 B2.

Davidson, I. 1961. Observations on the pathogenic staphylococci in a dairy herd during a six year period. Res. Vet. Sci. 2:22-40.

Fawell, S., J. Seery, Y. Daikh, C. Moore, L. L. Chen, B. Pepinsky, and J. Barsoum. 1994. Tat-mediated delivery of heterologous proteins into cells. Proc. Natl. Acad. Sci. USA 91:664-668.

Fox, L. K., M. Gershman, D. Hancock, and C. Hutton. 1991. Fomites and reservoirs of Staphylococcus aureus causing intramammary infections as determined by phage typing: The effect of milking time hygiene practices. Cornell Vet. 81:183-193.

Frost, A. J. 1975. Selective adhesion of microorganisms to the ductular epithelium of the bovine mammary gland. Infect. Immun. 12:1154-1156.

Graber, H. U., J. Naskova, E. Studer, T. Kaufmann, M. Kirchhofer, M. Brechbuhl, W. Schaeren, A. Steiner, and C. Fournier. 2009. Mastitis-related subtypes of bovine Staphylococcus aureus are characterized by different clinical properties. J. Dairy Sci. 92:1442-1451.
Harmon, R. J. 1994. Physiology of mastitis and factors affecting somatic cell counts. J. Dairy Sci. 77:2103-2112.

Hillerton, J. E., A. J. Bramely, R. T. Staker, and C. H. McKinnon. 1995. Patterns of intramammary infection and clinical mastitis over a 5-year period in a closely monitored herd applying mastitis control measures. J. Dairy Res. 62:39-50.

Hogan, J. S., R. N. Gonzalez, R. J. Harmon, S. C. Nickerson, S. P. Oliver, J. W. Pankey, and K. L. Smith. 1999. Staphylococci. Pages 65-85 in Laboratory Handbook on Bovine Mastitis. National Mastitis Council Inc. Madison, WI.

Jakubczak, A., P. Szweda, J. Kur, M. Kleczkowski, and A. Franowka. 2010. Possibilities of application of recombinant lysostaphin as an alternate agent in the therapy of Staphylococcus aureus mastitis. Advances in Agricultural Science 13:115-120.

Middleton, J. R., and L. K. Fox. 2002. Influence of Staphylococcus aureus strain on mammary quarter milk production. Vet. Rec. 150:411-413.

Middleton, J. R., L. K. Fox, J. M. Gay, J. W. Tyler, and T. E. Besser. 2002. Use of pulsed-field gel electrophoresis for detecting differences in Staphylococcus aureus strain populations between dairy herds with different cattle importation practices. Epidemiol. Infect. 129:387-395.

Middleton, J. R., and C. D. Luby. 2008. Escherichia coli mastitis in cattle being treated for Staphylococcus aureus intramammary infection. Vet. Rec. 162:156-157.

Middleton, J. R., J. Ma, C. L. Rinehart, V. N. Taylor, C. D. Luby, and B. J. Steevens. 2006. Efficacy of different Lysigin formulations in the prevention of Staphylococcus aureus intramammary infection in dairy heifers. J. Dairy Res. 73:10-19.

Nagahata, H., H. Ito, H. Maruta, Y. Nishikawa, H. Susukino, S. Matsuki, H. Higuchi, T. Okuhira, and A. Anri. 2007. Controlling highly prevalent Staphylococcus aureus mastitis from the dairy herd. J. Vet. Med. Sci. 69:893-898.

NRC. 2001. Nutrient Requirements of Dairy Cattle. 7th rev. ed. Natl. Acad. Press, Washington, DC.

Oldham, E. R., and M. J. Daley. 1991. Lysostaphin: Use of a recombinant bactericidal enzyme as a mastitis therapeutic. J. Dairy Sci. 74:4175-4182.

Ote, I., B. Taminiau, J. Duprez, I. Dizier, and J. G. Mainil. 2011. Genotypic characterization by polymerase chain reaction of Staphylococcus aureus isolates with bovine mastitis. Vet. Microbiol. 153:285-292.

Recsei, P. A., A. D. Gruss, and R. P. Novick. 1987. Cloning, sequence, and expression of the lysostaphin gene from Staphylococcus simulans. Proc. Natl. Acad. Sci. USA 84:1127-1131.

Roy, J. P., and G. Keefe. 2012. Systematic review: What is the best antibiotic treatment for Staphylococcus aureus intramammary infection of lactating cows in North America. Vet. Clin. North Am. Anim. Food Pract. 28:39-50.

Saperstein, G., L. Hinckley, and J. Post. 1988. Taking the team approach to solving staphylococcal mastitis infection. Vet. Med. 83:939-947.

Sargeant, J. M., K. E. Leslie, J. E. Shirley, B. J. Pulkrabek, and G. H. Lim. 2001. Sensitivity and specificity of somatic cell count and California Mastitis Test for identifying intramammary infection in early lactation. J. Dairy Sci. 84:2018-2024.

Schindler, C. A., and V. T. Schuhart. 1964. Lysostaphin: A new bacteriolytic agent for the staphylococcus. Proc. Natl. Acad. Sci. USA $51: 414-421$.

Sears, P. M., C. A. Smith, J. Polak, and P. Blackburn. 1988. Lysostaphin efficacy for treatment of Staphylococcus aureus intramammary infections. J. Dairy Sci. 71(Suppl. 1):244. (Abstr.)

Smith, T. H., L. K. Fox, and J. R. Middleton. 1998. Outbreak of mastitis caused by one strain of Staphylococcus aureus in a closed dairy herd. J. Am. Vet. Med. Assoc. 212:553-556.

Tenover, F. C., R. D. Arbeit, R. V. Goering, P. A. Mickelsen, B. E. Murray, D. H. Persing, and B. Swaminathan. 1995. Interpreting chromosomal DNA restriction patterns produced by pulsed-field gel electrophoresis: Criteria for bacterial strain typing. J. Clin. Microbiol. 33:2233-2239. 
Trinidad, P., C. Nickerson, and W. Adkinson. 1990. Histopathology of staphylococcal mastitis in unbred dairy heifers. J. Dairy Sci. 73:639-647.

USDA. 2008. Prevalence of Contagious Mastitis Pathogens on United States Dairy Operations, 2007. National Animal Health Monitoring System. USDA, Washington, DC.

van den Borne, B. H. P., M. Nielen, G. van Schaik, M. B. Melchior, T. J. G. M. Lam, and R. N. Zadoks. 2010. Host adaptation of bovine Staphylococcus aureus seems associated with bacteriologic cure after lactational antimicrobial treatment. J. Dairy Sci. 93:2550-2558.

Wadia, J. S., R. V. Stan, and S. F. Dowdy. 2004. Transducible TATHA fusogenic peptide enhances escape of TAT-fusion proteins after lipid raft macropinocytosis. Nat. Med. 10:310-315.
Wadstrom, T., and O. Vesterberg. 1971. Studies on endo- $\beta-N$ acetylglucosaminidase, staphylolytic peptidase, and $N$-acetylmuramyl-L-alanine amidase in lysostaphin and from Staphylococcus aureus. Acta Pathol. Microbiol. Scand. B Microbiol. Immunol. $79: 248-264$

Wall, R. J., A. M. Powell, M. J. Paape, D. E. Kerr, D. D. Bannerman, V. G. Pursel, K. D. Wells, N. Talbot, and H. W. Hawk. 2005 Genetically enhanced cows resist intramammary Staphylococcus aureus infection. Nat. Biotechnol. 23:445-451. 